\title{
39 Grasping the global: multi-sited ethnographic market studies
}

Dannie Kjeldgaard, Fabian Faurholt Csaba and Güliz Ger

\section{Introduction}

In recent years, the field of marketing and consumption research has seen a rise in studies applying ethnographic methods (Arnould and Wallendorf, 1994; Arnould and Thompson, 2005). A number of these studies have utilized a multi-sited research approach (Marcus, 1995). This chapter discusses the emergence and principles of multisited ethnography: how it differs from cross-cultural and single-sited ethnographic research, and how it applies to marketing and consumer research. A central argument is that multi-sited ethnographic market studies are particularly pertinent in investigations which specifically attempt to grasp global or globalizing market conditions and relations. Describing and analyzing the complexities of market phenomena of an interlinked and interdependent social world, a multi-sited ethnographic approach studies globalization 'from within' rather than as an external influencing factor on local market realities. Where traditional ethnographic work in anthropology suggests the deep immersion in and thick description of a single locality, multi-sited ethnography argues that to immerse oneself deeply in a transnational phenomenon one must abandon the privilege of the locality, embrace mobility and 'go with the flow' (Burawoy, 2000; Hannerz, 2003).

Globalization challenges the units of analysis of traditional cross-cultural research as well as the objects and premises of traditional ethnography. Multi-sited ethnographic inquiry can bring out the multifaceted character of globalization through the analysis of different experiences of its impact on communities, but also by studying the specific networks, flows and connections that constitute the social-cultural and economical infrastructure of globalization. Rather than merely describing the imprints of globalization, multi-sited ethnography moves with it, tracing its networks, flows and interconnections and the modes of interaction, institutions and stratification that characterize it. Multisited research hence represents an attempt to adjust ethnography and make it viable and relevant under the conditions of globalization. Multi-sited Ethnographic Market Studies (MEMS hereafter) is a set of guiding principles that can be followed more or less rigorously when studying global phenomena of the market.

We begin our discussion of MEMS by situating it in relation to the cross-cultural research tradition in marketing and consumer research, the challenges posed by an emergent transnational market reality and how this has led to suggestions in anthropology to move from single-sited to multi-sited research. In the second part of the chapter we introduce research strategies (drawn from Marcus, 1995) and relate these to existing research in marketing and consumer research. Finally we discuss some of the practical and analytical challenges posed by MEMS. 


\section{Marketing and consumer research: from cross-cultural to ethnographic perspectives}

The continuous expansion of international trade over several decades has given rise to a large body of academic and commercial research in international consumer behavior and marketing. In the effort to map international consumer and market variations and finding out how consumers in different countries react to marketing efforts, cross-cultural research has assumed great importance (van Herk, Poortinga and Verhallen, 2005; Malhotra, Agarwal and Peterson, 1996). But, as globalization has intensified and researchers have come to realize better its complex ties to culture and consumption, serious doubts have been raised about dominant theoretical models in the field. As Douglas and Craig noted in 1997, 'traditional approaches to studying cross-cultural behavior which are typically grounded in a comparative or cross-sectional approach have become increasingly inadequate to capture the complexity of cultural influences' (p. 381). Criticism has pointed to the lack of explanatory power and rigor, which, of course, are interrelated. We might distinguish between two veins of criticism: one that addresses the technical, methodological problems arising when collecting comparable data in different cultures, and a more fundamental critique, addressing the very theoretical premises behind cross-cultural consumer and marketing research.

The methodological problems in cross-cultural studies can be framed in terms of the distinction between etic and emic. An etic approach is based on criteria from outside a particular culture, often scientific procedure and norms. In contrast, 'emic' explains the behavior of members of a culture according to their own, indigenous concepts and definitions. Cross-cultural researchers are faced with the emic/etic dilemma: they might adapt research instruments to each national culture (emic approach) at the expense of the cross-cultural comparability and external validity, or stick to tests applicable to several countries at the expense of reliability and internal validity (Douglas and Craig, 1997; Usunier, 2000). Since comparison and generalization across cultures is a central aim of most studies, cross-cultural research has leaned towards the etic approach, but sought to alleviate problems of the comparability of data by identifying ways of establishing crosscultural equivalence. Usunier (2000) lists six main categories of cross-cultural equivalence, designating areas in which non-equivalence may arise in comparative research. These are conceptual, functional, translation, measurement, sample and data collection equivalence. Construct equivalence refers to the similarity of the interpretation of objects or behavior, and the comparability of the categories in which objects are placed. Functional equivalence has to do with similarity of the functions or purposes of use of objects across cultures. Translation equivalence is concern with lexical, idiomatic, syntactical and experiential similarity across languages and dialects. Measurement equivalence concerns translation, calibrating the equivalence of the units of measurement, and metric equivalence or the equivalence of the scale or the scoring procedure. Sample and data collection equivalence address the practical challenges of collecting survey data under different circumstances where the availability and accessibility of informants may vary greatly. Of these, construct equivalence or specification error is arguably the most important issue (Cavusgil and Das, 1997; van Herk, Poortinga and Verhallen, 2005). Although the equivalence categories demonstrate the numerous potential sources of error in and the complex nature of cross-cultural research, the effort to address equivalence issues reflects a belief that careful research procedures can help minimize non-equivalence and produce valid and reliable findings. While scholars have emphasized the critical role of taking steps to minimize non-equivalence or to measure the extent of non-equivalence and have 
warned researchers that, unless equivalence exists, the findings and conclusions of a study are worthless (e.g., Cavusgil and Das, 1997; van Herk, Poortinga and Verhallen, 2005; Steenkamp and Baumgartner, 1998), studies abound in journals which either ignore this issue or pay lip service to it. Even the rare studies which follow a rigorous approach and accept equivalence only if serious attempts to find non-equivalence have failed, are at a loss in explaining why non-equivalence occurs when it does. So, while acknowledging that many studies do not exhibit the necessary methodological rigor, this vein of criticism does not fundamentally question the central premises of cross-cultural research.

In a more far-reaching critique, Holt reflects on evidence that cross-cultural consumer research has little success in describing and explaining cultural differences in consumption patterns across countries, and attributes this to three underlying flaws in the predominant values/personality conception of culture. First, he argues that its nomothetic approach - which seeks to measure, describe and compare cultures according to a limited set of purportedly universal traits, values or needs - is too reductive to uncover differences and meaning in consumption. Secondly, the focus on preferred end-states ignores what is arguably the very essence of consumption: how consumers reach these end-states. Similar points have been made by other interpretivist scholars, in advancing anthropological and ethnographic approaches in consumer and marketing research. Venkatesh (1995) reproaches cross-cultural consumer research for imposing its positivistic research tools and measures developed in Western countries uncritically on other cultural settings and thus being ethnocentric. Sherry $(1995$, p. 15) implies that anthropological methods offer a better way of fulfilling marketing's ideal of 'getting closer to the consumer' (or other marketplace stakeholders) and to deal with challenges of cultural propriety and appropriate development in international marketing. Holt's final point of criticism regards the level-of-analysis and conceptions of self and culture as holistic entities. The values/personality approach takes both self and culture to be rather coherent, stable and well-defined constructs, but much of contemporary thought on social identity rejects this view, and suggests that 'self' is a contingent, situational and contradictory structure. This, of course, raises serious questions about the validity of survey research based on the responses of capricious individuals. And the classical assumption of cultures as unified wholes has become more and more dubious in complex, differentiated societies, especially, as we shall argue, with the continuous advancement of globalization. The acknowledgment that today multiple and diffuse cultural systems operate across a given population poses fundamental challenges to both anthropological thought and cross-cultural consumer and marketing research (Holt, 1994, p. 81). Douglas and Craig (1997) recognize that the evolving globalization of cultures demands new research designs for crosscultural consumer inquiry, and suggest studies of cultural units at various levels and 'multiple site studies' as paths forward. In taking stock of two decades of what they label 'consumer culture theory' (CCT), Arnould and Thompson (2005) argue that a new concept of culture now reigns in the field, which 'explores the heterogeneous distribution of meanings and the multiplicity of overlapping cultural groupings that exist within the broader socio-historic frame of globalization and market capitalism' (p. 869).

\section{Global market realities}

Globalization and the processes and changes associated with the term are said to change the nature of social life and hence the reality of markets and consumption. The central 
issue in marketing has been whether international marketing strategies should follow the principle of global standardization or local adaptation (e.g. Levitt, 1983; Usunier, 2000). The issue echoes a wider debate in social theory about the homogenization or heterogenization of social life (for a review and critique of the debate, see Askegaard and Kjeldgaard, 2002). Approaches resisting the either-or position have also emerged. One example is Robertson's (1992) notion of 'glocalization', which argues that the local is always also global and the global is always local in its manifestations. While many accounts view the local and the global as separate entities, others imply that the dichotomy of the local and the global is broken down. Waters, for example, defines globalization as 'a social process in which the constraints of geography on social and cultural arrangements recede and in which people become increasingly aware that they are receding and in which people act accordingly' $(2001$, p. 5). This definition implies, first of all, that the decreasing constraints of geography mean that the social processes entailed essentially reconfigure notions of time and space. Secondly, it implies reflexivity on behalf of both institutional and individual actors.

One way of describing the processes of globalization is Appadurai's (1990) seminal account of the global cultural economy. Appadurai argues that economy, polity and culture increasingly operate disjunctively and detached from localities and nation states. They operate through cultural flows in five 'scapes': ethnoscapes (the flow of people), technoscapes (the flows of technology: both conventional and also social technology, such as management principles and theories), finanscapes (flows of money), mediascapes (the flow of images and, more importantly, representations of a greater variety of imagined lives) and ideoscapes (the flow of ideas). Within marketing Ger and Belk (1996) have since added the term 'consumptionscapes' in order to highlight the specific flow of cultures of consumption. Often the global in marketing and consumer research is (more or less explicitly) understood as something external to the local. Ger and Belk (1996) argue that global consumer culture is used together with local culture to navigate and positioning the individual in the local identity hierarchies. Askegaard, Arnould and Kjeldgaard (2005) analyse the acculturation processes of Greenlanders in Denmark by identifying three ideologies that are formative of identity negotiation, one of which is global consumer culture. Thompson and Arsel (2004) analyze the glocalization of consumer culture by Starbucks in a given locality. While these studies take globalization seriously, both as consequence for and object of the study of market phenomena, with the theories just outlined above, however, we argue that the social reality is by and large deterritorialized and hence has become transnational. This means that the global culture is an allencompassing system of which what we call the local is a part (Hardt and Negri, 2000). Then any study of a locality is a study of the lived meaning of the system.

Globalization represents 'a multifaceted or differentiated social phenomenon', which 'cannot be conceived as a singular condition but instead refers to patterns of global interconnectedness within all the key domains of social activity' (Held et al., 1999, p. 27). Any meaningful account of contemporary globalization and its unique attributes or dominant features requires that a set of key spatiotemporal and organizational dimensions are analyzed. This involves studying the organization of networks of relations and connections, flows and levels of activities, interchanges and the impact of these phenomena on communities (ibid., p. 17). Since the processes of globalization lead towards an increased transnational social reality, marketing and consumption phenomena can no longer be 
understood sufficiently through reliance on single-sited analysis. The globalized condition calls for 'innovative forms of multi-locale ethnography necessary to do justice to transnational political, economic and cultural forces that traverse and constitute local and regional worlds' (Clifford, 1997, p. 27).

\section{Transformations of ethnography: the emergence of multi-sited research}

The concept of multi-sited ethnography was advanced by Marcus $(1986,1995,1999)$ as a designation for an emergent stream in anthropological research, which, in the face of the challenges posed by globalization, breaks with conventional ethnographic methodology (for a discussion of wider methodological debates in anthropology, see Ekström in this volume). Marcus distinguishes multi-sited ethnography from the conventional, 'singlesited research' approach to fieldwork which relies on the intensive investigation of one particular place or a local situation. The multi-sited approach, he argues, has emerged in response to empirical changes in the world and therefore to transformed locations of cultural production $(1995$, p. 97). In a world in which few places are untouched by global forces and flows, ethnographic research focusing on single sites and local experiences, culture and roots is constrained and constraining (Gupta and Ferguson, 1997). While conventional single-sited research is capable of registering the impact of globalization in the local context of its research settings, it must rely on theoretical work (on world systems, globalization) to frame the experiences of local subjects and cultural impact of encounters with the global. With such a 'one-sited' perspective, intercultural connections are conceived mainly in terms of the way local cultures accommodate and resist the encroachments of modernity, Western (neo-) colonialism, or global capitalism. Multisited research, on the other hand, through the study of multiple locales, extends the scope of ethnography to include not only the life world of situated subjects, but also associations and connections among sites that make up the system. While acknowledging macrotheoretical accounts of globalization, multi-sited research engages in its own empirical investigations of the relationships, discourses, infrastructures and agents that connect, constitute and construct the global (and local).

Multi-sited fieldwork does not represent an entirely new conception, yet it marks a break with the norms and assumptions instituted by classical anthropology. Hannerz (2003) discusses these fieldwork norms in terms of the prescriptions of Evans-Pritchard. This classical model demands prolonged and close contact with the people in the site, communication through the natives' language, and the study of their entire culture and social life. It represents the idea of a thorough, formative, exclusive engagement with a single field. Hannerz suggests that, while this ideal has been important for the identity of the discipline, it does not represent the full range of research practices anthropologists have engaged in. Ethnographic practice outside anthropology has conformed even less to this ideal. Hannerz offers examples of multi-sited research even in pioneering anthropology studies, such as Malinowski's trailing of the Kula ring among the Trobriander Islanders. He also argues that the transnational, translocal and global themes addressed through multi-sited ethnography have appeared in anthropological studies of diffusion, acculturation, culture contact, social change and modernization throughout much of the twentieth century. The common premise of these studies, as for multi-sited ethnography, is the recognition that the "world is not a mosaic of bounded identities, existing in isolation from each other' (Hannerz, 1998, p. 237). Transnational research rejects the classical 
quest for pure traditions and discrete cultural differences, which Clifford deems 'exoticist' and 'orientalist' (1997, p. 5).

Single-sited ethnography should not be identified too closely with the classical quest, however. Hannerz discusses a genre of transnational anthropology 'communities open to the world', which addresses the local impact of outside forces. Using rather conventional research approaches, such studies have looked at the way local cultures have resisted, accommodated or made creative use of powerful foreign cultural influences. While analysis of resistance tends to reflect the desire to preserve cultural integrity and resist external influences, the genre also acknowledges the capacity of globalization to produce new cultural forms and diversity in the local context, through creolization and hybridity. The genre does seem to maintain certain taken-for-granted notions of the local rooted in an emic perspective. Other genres of transnational anthropology are translocalities (places such as airports, world cities, world's fairs which are hubs or nodes in transnational social and cultural processes), border studies, migration, diasporas, transnational corporations and occupations, cyberspace and commodities (Hannerz, 1998). Mobility, flows and relations between places are central to each of these genres and call for multi-sited approaches.

Table 39.1 provides an overview of the main contrasts between single-sited ethnography and the multi-sited approach. We might, however, ask whether there really is a significant difference in the methodology of fieldwork in the two approaches. Moeran, commenting on Marcus's distinction, suggests that even what he calls 'frame-based' fieldwork, conducted in easily identified physical locations, involves following people and things around. Although he implies that network-based fieldwork, which involves following a flow of social interaction along networks of people and things, is much less solidly anchored in a locality, he does not believe that the character of the fieldwork or the fieldworker changes fundamentally (Moeran, 2005).

While the theories on culture have generated a new line of consumption and market research based on single-sited research (see Arnould and Thompson, 2005, for a selective summary), theories of globalization have not generated a similar line of multi-sited research, at least not to the same extent. This is curious as there have been repeated calls to 'demystify and 'ground' globalization in the theoretical literature on globalization (Freidberg, 2001, p. 354). Perhaps the challenges posed by multi-sited research are greater than those of single-sited research. However, if we want to understand globalization, as well as international marketing informed by theories of globalization, multi-sited ethnographical research provides a rewarding route.

\section{MEMS: methodological principles and challenges}

Although few aspects of social life are unaffected by the processes of globalization, MEMS will not be applicable to all types of research questions. However, more and more research questions will emanate from the phenomena of the market that are increasingly transnational.

\section{Research strategies}

Following Marcus (1995), we introduce five strategies for constructing multi-site ethnographic studies. These are avenues to be pursued in order both to accomplish a generation of knowledge of transnational phenomena and to establish a transnational terrain for 
Table 39.1 Comparison of single-sited and multi-sited ethnography

\begin{tabular}{|c|c|c|}
\hline & Single-sited & Multi-sited \\
\hline Approach to fieldwork & $\begin{array}{l}\text { Intensively-focused upon } \\
\text { single site of ethnographic } \\
\text { observation and participation }\end{array}$ & $\begin{array}{l}\text { Objects of study are mobile } \\
\text { and multiply situated } \\
\text { Fieldwork conducted at } \\
\text { multiple sites. Not all sites } \\
\text { are treated by a uniform set } \\
\text { of fieldwork practices. } \\
\text { Varying intensities and } \\
\text { qualities of fieldwork }\end{array}$ \\
\hline $\begin{array}{l}\text { Central themes of the } \\
\text { research }\end{array}$ & $\begin{array}{l}\text { Illuminating the entire culture } \\
\text { and social life of a people or } \\
\text { the perspective of the } \\
\text { subaltern. Resistance and } \\
\text { accommodation. Groups' } \\
\text { encounter of and responses to } \\
\text { displacement of their culture }\end{array}$ & $\begin{array}{l}\text { The circulation of cultural } \\
\text { meanings, practices, objects } \\
\text { and identities in diffuse } \\
\text { time-space }\end{array}$ \\
\hline Research perspective & $\begin{array}{l}\text { Committed localism, holistic } \\
\text { Dualistic them-us frame }\end{array}$ & $\begin{array}{l}\text { Self-conseiously embedded } \\
\text { in a world system. Exercise } \\
\text { in mapping terrain, goal not } \\
\text { holistic representation }\end{array}$ \\
\hline Comparative perspective & $\begin{array}{l}\text { Comparative studies are } \\
\text { generated for homogeneously } \\
\text { conceived conceptual units, } \\
\text { on the basis of separate } \\
\text { projects of fieldwork }\end{array}$ & $\begin{array}{l}\text { Comparative dimension is } \\
\text { integral to study. It involves } \\
\text { juxtaposition of phenomena } \\
\text { previously seen as 'worlds } \\
\text { apart' }\end{array}$ \\
\hline $\begin{array}{l}\text { Reliance on theory of } \\
\text { globalization (world system) }\end{array}$ & $\begin{array}{l}\text { Relies on theory of world } \\
\text { system for contextualizing } \\
\text { portraiture in terms of which } \\
\text { experiences of local subjects } \\
\text { are described and analyzed }\end{array}$ & $\begin{array}{l}\text { Acknowledges narratives of } \\
\text { world system but does not } \\
\text { rely on them. Constructs the } \\
\text { lifeworld of situated subjects, } \\
\text { but also ethnographically } \\
\text { constructs aspects of the } \\
\text { system itself through the } \\
\text { connections among sites }\end{array}$ \\
\hline
\end{tabular}

studying global consumer culture. We relate these strategies to studies in marketing and consumer research which are exemplars of multi-sited research, although not necessarily explicitly framed as such.

Follow the people The flow of people is a particular aspect of the global cultural system that lends itself to a multi-site approach. In line with Appadurai's (1990) notion of the ethnoscapes, certain groups of consumers and marketers are particularly mobile and construct their identities transnationally. Studies that can be said to have used the 'follow the people' strategy are studies of transmigrants (Ücok and Kjeldgaard, 2006), marketers' transnational activities and their structuring of global markets (Applbaum, 2000) and the 
study of surfer culture (Canniford, 2005). These studies acknowledge that market phenomena are constructed and lived transnationally. Hence one must follow the people as they move to, from and through multiple sites or their multiple local manifestations.

Follow the thing Material manifestations of contemporary consumer culture are results of the output of transnational commodity chains. In order to get beyond the surface brand identities of mass consumer goods, Klein (1999) traced, for example, Nike shoes back through the chain of commodification and hence uncovered previously unknown brand meanings. Similarly Marcus points to Sidney Mintz's study of sugar. Csaba and Ger (2000) have followed the Turkish carpet and the meanings attached to this commodity from its culture of production to culture of distribution and consumption. Tracing these commodity chains generates knowledge of the workings and linkages of transnational marketing networks and consumer culture and thereby a way of entering the transnational flows of global culture.

Follow the metaphor ${ }^{1}$ Similar to following things, this mode obtains when the things followed are signs, symbols or metaphors, that is, the transnational aspects of discourse. Here we can point to studies of consumer desire (Belk, Ger and Askegaard, 2003) and consumer cosmopolitanism (Thompson and Tambyah, 1999) which trace elements of discourse which shape consumer identities and lifeworlds. Furthermore the construction and production of transnational brand identities have been studied: for example, how a common cultural identity of Asianness is constructed by brand managers and advertising executives (Eckhardt and Cayla, 2005). Another possibility is to study certain market metaphors or terminology in multiple sites: for example, how certain segments are represented globally and appropriated locally (e.g. Kjeldgaard and Askegaard's 2006 study of the glocalization of the transnational ideology of youth culture in Denmark and Greenland and in urban and rural contexts in each of these cultural contexts. This facilitated an analysis of how an ideological market phenomenon may be appropriated and creolized according to local culture but this occurred according to certain structural constraints).

Follow the life or biography The biographical method involves tracing the emergence of a given phenomenon through multiple sites. This could be the historical emergence of certain phenomena of the market in one cultural context and its cultural history and its diffusion and morphology throughout global cultural economy (for example the emergence and spread of youthful consumption: Liechty, 1995). Another example is the tracing of commodities as suggested by Kopytoff (1986) or brand histories such as Holt's (2004) tracing of the biography of certain iconic brands and their relation to popular culture.

Follow the conflict While Marcus primarily makes reference to the anthropology of law in connection with following conflicts, global consumer culture is generative and partly constituted by conflicts. Culture jamming and the rise of alternative global brands which define themselves as a negation of dominant brands - so-called 'Doppelgänger' brands (Thompson, Rindfleisch and Arsel, 2006) -- illustrate that the tensions created by the logic of marketing are negotiated through resistance based on the very same logic. Furthermore the resistance to the form of contemporary global market and its semi-state institutions 
(such as the alternative to the World Economic Forum, the World Social Forum, or the way protestors follow the G8 summits around the world) represents examples of social relations constituted by conflict that are stretched across traditional sociogeographic boundaries.

The strategically situated single-site study Although the tracing and following across multiple sites lie at the heart of multi-sited ethnography, there can be instances when the mapping of the broader system is best studied in particular contexts. One example of strategically situated (single-site) ethnography is the study of how glocalization shapes a particular brand competition domain and hence generates new local variation as the outcome (Thompson and Arsel, 2004). Another is the study of the social technique of branding in market cultures where branding is an emergent phenomenon (Askegaard, 2005 ). Such studies provide knowledge of the logic of transnational markets and hence provide knowledge of the system as it becomes manifest in local cultural contexts.

\section{Challenges}

Multi-sited fields pose various challenges in research design, depth, reflexivity and interpretation.

Research design One issue is the unforeseen connections discovered in the field which lead to unexpected trips at unexpected times. For example, a carpet fair held once a year at a particular town, the link of an Ankara retailer to a middleman from Kayseri who buys from weavers in mountain villages two hours' driving distance from Kayseri, and a Philadelphia-based owner-manager visiting the Eastern Anatolian villages three times a year require great flexibility on the part of the researcher (see Csaba and Ger, 2000). Furthermore unforeseen sites lead to unforeseen topics and conceptual foci such as the weavers' dilemmas and gender relations entailed in global carpet production and consumption. Thus research designs will be highly emergent.

Another major issue is achieving depth. In order to achieve a relatively satisfactory understanding of the given phenomenon, research can be undertaken individually or in teams. When done individually, what could be termed 'ethnographic nomadism', one has the advantage of constantly improving understanding based on previous understandings. The disadvantage of this is the risk of not achieving sufficient detail, not following the phenomenon extensively enough. This strategy was applied in Ücok's study of Turkish transmigrants (Ücok and Kjeldgaard, 2006) by following informants in multiple sites (their homes, at work, at social occasions) as well as doing this in the multiple cultural contexts which informants moved to and from (Denmark and Turkey). This nomadism facilitated a fuller understanding of an identity forged as 'in-between' being constituted by the very movement between localities.

Another option is to conduct the research in a team in which one or more researchers study each site in depth and then compare and combine the findings. For example, three researchers from three different countries working on consumer desires (Belk, Ger and Askegaard, 2003) generated a multi-site study by each one doing essentially a single-site study but in a coordinated way. The coordination involved methodological as well as theoretical concerns. While following the phenomenon, 'desire', each of the three countries posed different challenges. For example, in Turkey, the researchers needed to sample from 
among lower-class informants with a rural background as the notion of modern subjectivity is important for the phenomenon of desire, and this group would provide a comparison and counterpoint to the middle-class informants. However this was not called for in Denmark or the USA. On the other hand, Denmark posed a greater problem than Turkey or the USA in terms of access to informants, owing to the institutional structures and expectations. This study benefited from having an insider doing the fieldwork in each of the three sites combined with researchers cross-checking each other's assumptions, perspectives and interpretations in various ways. In this way, it is possible to study each site in more detail, but there is the danger of this becoming a comparative study based on a standardized methodology, not capturing the flows and connections among the sites.

A third option is to follow the phenomenon in teams, for example a group of researchers with multiple cultural and/or disciplinary backgrounds, as Csaba and Ger (2000) did in their study of networks of production and consumption relationships of carpets. The advantage is that each site can be studied in more detail, that there is the possibility of constructing and reconstructing the interpretation as the team moves from site to site and having a multiplicity of perspectives on the phenomenon. Hence working on a topic as a multi-culture team not only enables multi-sited research but also brings additional benefits: as the researchers have different cultural lenses, the ultimate interpretation of the data goes through more as well as more interesting iterations and these iterations are subjected to each other's criticisms.

The last option is one in which the individual researcher does the following but teams up with locally based collaborators in each site. This strategy was followed in a study of heritage and theme parks in diverse localities (Hendry, 2003).

There might be more options and obviously combinations of the four outlined above. A study that exemplifies the reliance on both teamwork and ethnographic nomadism is Ger and Belk's (1999) work on materialism in four sites. With each researcher investigating two sites, this research followed a conflict-ridden phenomenon and the conflict itself: how is it that people consume excessively while they think that placing a lot of emphasis on consumption is bad? Unlike the study on consumer desire, this one involved each coauthor working in a site where s/he was an insider and another one in which s/he was an outsider. Again, the study benefited from divergent cultural perspectives of the researchers. The very fact that there were multiple sites and that the researchers were themselves from different cultures enabled uncovering the underlying culturally specific ethics that justify, moralize and legitimize consumption.

Trustworthiness and glocal reflexivity In terms of trustworthiness, MEMS pose the question of how to achieve in-depth knowledge of geographically and culturally dispersed phenomena. How is one to balance the requirement of thick description of the local versus the need to map the relations and connections? While this to some extent is determined by the goals of the research, it points to the need to negotiate 'the distribution of attention' (Hannerz, 1998). On one hand, ethnography is incomplete if it does not take into account the experiences of local actors. On the other hand, if there is no account of relations and connections among sites and life world experiences in these sites, the results will be parochial.

One important aspect of multi-sited ethnographic studies is the constant reflexivity required by the researcher as she moves, traces and follows the connections and relations of the phenomenon across sites. How are variations of the phenomenon constructed in 
the global-local dialectic (Thompson and Arsel, 2004)? Which local cultural or political economical contexts enter into the dialectical process? Moving across sites and thinking through the different experiences in the various sites not only requires but also facilitates a depth in reflexivity. For example, noteworthy differences in the nature of the relationships among the carpet weavers and the dealers in different villages helped Csaba and Ger (2000) identify and interpret the link between carpet quality and power relations in carpet production networks. Reflexivity therefore is a matter of distinguishing similarities from differences so that the study of the phenomenon in one site adds to the totality of understanding of the overall phenomenon. Therefore each local instantiation must be studied intratextually and then read intertextually across sites - much like what is suggested when studying a phenomenon by interviewing individuals (Thompson et al., 1989); however, in this case this must be done specifically with a glocal perspective.

In summary, MEMS pose challenges such as time, access to multiple fields, logistics of numerous trips, lack of prolonged engagement in any particular locale and the accompanying interpretive challenges. These challenges can be overcome by flexibility, negotiating the diverse fields, teamwork, intratextual and intertextual reading of the multiple sites, as well as intraresearcher and interteam glocal reffexivity.

\section{Conclusion}

The key aspects of globalization, namely, global interconnectivity, the transnational nature of social reality and the local-as-part-of-the-global compel us to use multi-sited methods. Multi-sited ethnography is more than a necessary adjustment to ethnography; it can contribute greatly to our very understanding of the complex phenomenon of globalization and the application of this approach in marketing and consumer research offers rich insights into the processes and contours of economic and cultural globalization. A multi-sited approach can contribute to refining our picture of globalization. When studying phenomena of the market which is constituted transnationally it makes less sense to carry out the single-sited ethnography or cross-cultural comparative studies. Rather, to offer adequate accounts of such phenomena one approach is to utilize MEMS. How particular projects are to be designed depends on the nature of the research question and which, or which combination of, phenomena are to be investigated. The important thing is that by constructing a research setup one also constructs the particular terrain or part of the terrain one wants to research. It is therefore more a matter of applying a 'multi-sited imaginary' as a perspective on market phenomena that does not have localities as privileged units of analysis. Rather the unit of analysis is the relations that emerge from the manifestations of the global in the local.

MEMS allow us to get into the global flows, to study the consumptionscapes and marketscapes of the global cultural economy from within rather than as an external cultural representation entering specific localities. While following the phenomenon through the flows poses various methodological challenges, these challenges are not insurmountable. Thus MEMS provide the capacity to make theoretical arguments through revealing and demarcating connections and relational categories rather than essentialized differences.

\section{Note}

1. Here we have collapsed 'follow the metaphor' with Marcus's 'follow the plot/story/allegory', since this is defined as a subset of the 'follow the metaphor' mode. 


\section{References}

Appadurai, Arjun (1990), 'Disjuncture and difference in the global economy', in M. Featherstone (ed.), Global Culture: Nationalism. Globalization and Modernity, London: Sage, pp. 295-310.

Applbaum, Kalman (2000), 'Crossing borders: globalization as myth and charter in American transnational consumer marketing', American Elhnologist, 27 (2) (May), 257-82.

Arnould, Eric J. and Craig J. Thompson (2005), 'Consumer culture theory (CCT): twenty years of research', Journal of Consumer Research, 31 (March), 868-82.

Arnould, Eric J. and Melanie Wallendorf (1994), 'Market-oriented ethnography: interpretation building and marketing strategy formulation', Joumal of Marketing Research, XXXI (November), 484-504.

Askegaard, Seren (2005), 'Brands as a global ideoscape', in J. Schroeder and M. Salzer-Moerling (eds), Brand Culture, London: Routledge.

Askegaard, Søren and Dannie Kjeldgaard (2002), "The water fish swim in: relations between marketing and culture in the age of globalization', in S. Askegaard, N. Jøgensen and T. Kaudson (eds), Perspectives on Marketing Relations, Copenhagen: Thomson, pp. 13-35.

Askegaard, Søren, Eric J. Arnould and Dannie Kjeldgaard (2005), 'Post-assimilationist ethnic consumer research: qualifications and extensions', Journal of Consumer Research, 32 (1) (June), 160-71.

Belk, Russel W., Güliz Ger and Søren Askegaard (2003), 'The fire of desire: a multisited inquiry into consumer passion', Journal of Consumer Research, 30 (December), 326-51.

Burawoy, Michael (2000), Global Elhnography. Forces, Connections, and Imaginations in a Postmodern World, Berkeley: University of California Press.

Canniford, Robin (2005), 'Moving shadows: suggestions for ethnography in globalized cultures', Qualitative Market Research: An International Journal, 8 (2), 204-18.

Cavusgil, S. Tamer and A. Das (1997), 'Methodological issues in empirical cross-cultural research: a survey of the management literature and a framework', Maragement International Review, 37 (1), 71-96.

Cliford, James (1997), Routes. Travel and Translation in the Late Twentieth Century, Cambridge: Harvard University Press.

Csaba, Fabian Faurholt and Güliz Ger (2000), 'Global village carpets: marketing, tradition and the oriental carpet renaissance', in Clifford J. Schulz and Bruno Grbac (eds), Marketing Contributions to Democratization and Socioeconomic Developmem, Phoenix: Arizona State University.

Douglas, Susan P. and C. Samuel Craig (1997), 'The changing dynamics of consumer behaviour: implications for cross-cultural research', International Journal of Research in Marketing, 14, 379--95.

Eckhardt, Giana M. and Julien Cayla (2005), 'Asian brands without borders: recentering models of international marketing', working paper, Australian Graduate School of Management.

Freidberg, Susanne (2001), 'On the trail of the global green bean: methodological considerations in multi-site ethnography', Global Networks, 1 (4), 353-68.

Ger, Guiliz and Russell Belk (1996), 'I'd like to buy the world a Coke: consumptionscapes of the "less affluent world" ', Journal of Consumer Policy, 19 (3), $271-304$.

Ger, Güliz and Russell Belk (1999), 'Accounting for materialism in four cultures', Journal of Material Culture, 42, 183-204.

Gupta, Akhil and James Ferguson (1997), Anthropological Locations. Boundaries and Grounds of a Field Science, Los Angeles: University of California Press.

Hannerz, Ulf (1998), 'Transnational research', in H. Russell Bernard (ed.), Handbook of Methods in Cultural Anthropology, London: Sage, pp. 235--58.

Hannerz, Ulf (2003), 'Being there . . . and there . . and there! Reflections on multi-site ethnography', Ethnography, 4 (2), 201-16.

Hardt, Michael and Antonio Negri (2000), Empire, Cambridge, MA: Harvard University Press.

Held, David, Anthony McGrew, David Goldblatt and Jonathan Perrathon (1999), Global Transformations, Cambridge: Polity.

Hendry, Joy (2003), 'An ethnographer in the global arena: globography perhaps?', Global Networks, 3 (4), 497-512.

Holt, Douglas B. (1994), 'Consumers' cultural differences as local systems of tastes: a critique of the personality/values approach and an alternative framework', Asia Pacific Advances in Consumer Research, 1, 178-84.

Holt, Douglas B. (2004), How Brands Become Icons. The Principles of Cultural Branding, Boston, MA: Harvard Business School Publishing.

Kjeldgaard, Dannie and Søren Askegaard (2006), "The glocalization of youth culture: the global youth segment as structures of common difference', Journal of Consumer Research, 22 (September), 231-47.

Klein, Naomi (1999), No Logo. Taking Aim at the Brand Bullies, London: Flamingo.

Kopytoff, Igor (1986), 'The cultural biography of things: commoditization as process', in A. Appadurai (ed.), The Social Life of Things: Commodities in Cultural Perspective, Cambridge: Cambridge University Press, pp. 64-91.

Levitt, Theodore (1983), 'The globalization of markets', Harvard Business Review, May/June. 
Liechty, Mark (1995), 'Media, markets and modernization. Youth identities and the lived experience of modernity in Kathmandu, Nepal', in Vera Amit-Talai and Helena Wulff (eds), Youth Cultures. A Cross-cultural Perspective, London: Routledge, pp. 166-201.

Malhotra, Naresh K., James Agarwal and Mark Peterson (1996), 'Methodological issues in cross-cultural marketing research: a state-of-the-art review', International Marketing Review, 13 (5), 7-43.

Marcus, George E. (1986), 'Contemporary problems in ethnography and in the modern world system', in James Clifford and George E. Marcus (eds), Writing Culture, Berkeley: University of California Press, pp. 165-93.

Marcus, George E. (1995), 'Ethnography in/of the world system: the emergence of multi-sited ethnography', Annual Review of Anthropology, 24, 95-117.

Marcus, George E. (1999), 'What is at stake - and is not - in the idea and practice of multi-sited ethnography', Canberra Anthropology, 22 (2), 6-14.

Moeran, Brian (2005), The Business of Ethnography. Strategic Exchanges, People and Organization, Oxford: Berg.

Robertson, Roland (1992), Globalization: Social Theory and Global Culture, London: Sage.

Sherry, John F. (ed.) (1995), Contemporary Marketing and Consumer Behavior: an Anthropological Sourcebook, London: Sage.

Steenkamp, Jan Benedict and H. Baumgartner (1998), 'Assessing measurement invariance in cross-national consumer research', Joumal of Consumer Research, 25 (June), 78-90.

Thompson, Craig J. and Zeynep Arsel (2004), 'The Starbucks brandscape and consumers' (anti-corporate) experiences of glocalization', Journal of Consumer Research, 31 (December), 631-42.

Thompson, Craig J. and Siok K. Tambyah (1999), 'Trying to be cosmopolitan', Journal of Consumer Research, 26 (December), 214-40.

Thompson, Craig J., William B. Locander and Howard R. Pollio (1989), 'Putting consumer experience back into consumer research: the philosophy and method of existential phenomenology', Journal of Consumer. Research, 16 (September), 133-46.

Thompson, Craig J., Aric Rindfleisch and Zeynep Arsel (2006), 'Emotional branding and the strategic value of the doppelgänger brand image', Journal of Marketing, 70 (January).

Ücok, Mine and Dannie Kjeldgaard (2006), 'Consumption in transnational social spaces: a study of Turkish transmigrants', in Karin Ekström and Helene Brembeck (eds), European Advances in Consumer Research, vol. 7, Duluth, MN: Association for Consumer Research, pp. $431-6$.

Usunier, Jean-Claude (2000), Marketing Across Cultures, 3rd edn, London: Pearson Education.

Van Herk, Hester, Ype H. Poortinga and Theo M.M. Verhallen (2005), 'Equivalence of survey data: relevance for international marketing', European Journal of Marketing, 39 (3/4), 351 -64.

Venkatesh, Alladi (1995), 'Ethnoconsumerism: a new paradigm', in Janeen A. Costa and Gary J. Bamossy (eds), Marketing in a Multicultural World. Ethnicity, Nationalism, and Cultural Ldentity, London: Sage, pp. 26-67.

Waters, Malcolm (2001), Globalization, London: Routledge. 